\title{
Alterations in the Gut-Microbial-Inflammasome-Brain Axis in a Mouse Model of Alzheimer's Disease
}

\author{
Pradeep K. Shukla ${ }^{1, * \mathbb{D}}$, David F. Delotterie ${ }^{2} \mathbb{D}$, Jianfeng Xiao ${ }^{2}$, Joseph F. Pierre ${ }^{3}$, RadhaKrishna Rao ${ }^{1}$, \\ Michael P. McDonald 2,4,5 and Mohammad Moshahid Khan 2,5,6,*1D
}

1 Department of Physiology, College of Medicine, University of Tennessee Health Science Center, Memphis, TN 38163, USA; rrao2@uthsc.edu

2 Department of Neurology, College of Medicine, University of Tennessee Health Science Center, Memphis, TN 38163, USA; ddelotte@uthsc.edu (D.F.D.); jxiao@uthsc.edu (J.X.); mikemc@tennessee.edu (M.P.M.)

3 Department of Pediatrics, College of Medicine, University of Tennessee Health Science Center, Memphis, TN38163, USA; jpierre1@uthsc.edu

4 Department of Anatomy \& Neurobiology, College of Medicine, University of Tennessee Health Science Center, Memphis, TN 38163, USA

5 Neuroscience Institute, University of Tennessee Health Science Center, Memphis, TN 38163, USA

6 Center for Muscle, Metabolism, and Neuropathology, Division of Rehabilitation Sciences and Department of Physical Therapy, College of Health Professions, University of Tennessee Health Science Center, Memphis, TN 38163, USA

* Correspondence: pshukla2@uthsc.edu (P.K.S.); mkhan26@uthsc.edu (M.M.K.); Tel.: 1-901-448-3180; Fax: 1-901-448-1662 (M.M.K.)

check for updates

Citation: Shukla, P.K.; Delotterie, D.F.; Xiao, J.; Pierre, J.F.; Rao, R.; McDonald, M.P.; Khan, M.M.

Alterations in the Gut-MicrobialInflammasome-Brain Axis in a Mouse Model of Alzheimer's Disease. Cells 2021, 10, 779. https://doi.org/ 10.3390/cells10040779

Academic Editor: Juan Pablo de Rivero Vaccari

Received: 25 February 2021

Accepted: 27 March 2021

Published: 1 April 2021

Publisher's Note: MDPI stays neutral with regard to jurisdictional claims in published maps and institutional affiliations.

Copyright: (c) 2021 by the authors. Licensee MDPI, Basel, Switzerland. This article is an open access article distributed under the terms and conditions of the Creative Commons Attribution (CC BY) license (https:/ / creativecommons.org/licenses/by/ $4.0 /)$.

\begin{abstract}
Alzheimer's disease (AD), a progressive neurodegenerative disorder characterized by memory loss and cognitive decline, is a major cause of death and disability among the older population. Despite decades of scientific research, the underlying etiological triggers are unknown. Recent studies suggested that gut microbiota can influence AD progression; however, potential mechanisms linking the gut microbiota with AD pathogenesis remain obscure. In the present study, we provided a potential mechanistic link between dysbiotic gut microbiota and neuroinflammation associated with $\mathrm{AD}$ progression. Using a mouse model of $\mathrm{AD}$, we discovered that unfavorable gut microbiota are correlated with abnormally elevated expression of gut NLRP3 and lead to peripheral inflammasome activation, which in turn exacerbates AD-associated neuroinflammation. To this end, we observe significantly altered gut microbiota compositions in young and old 5xFAD mice compared to age-matched non-transgenic mice. Moreover, 5xFAD mice demonstrated compromised gut barrier function as evident from the loss of tight junction and adherens junction proteins compared to non-transgenic mice. Concurrently, we observed increased expression of NLRP3 inflammasome and IL-1 $\beta$ production in the 5xFAD gut. Consistent with our hypothesis, increased gut-microbialinflammasome activation is positively correlated with enhanced astrogliosis and microglial activation, along with higher expression of NLRP3 inflammasome and IL- $1 \beta$ production in the brains of 5xFAD mice. These data indicate that the elevated expression of gut-microbial-inflammasome components may be an important trigger for subsequent downstream activation of inflammatory and potentially cytotoxic mediators, and gastrointestinal NLRP3 may promote NLRP3 inflammasome-mediated neuroinflammation. Thus, modulation of the gut microbiota may be a potential strategy for the treatment of AD-related neurological disorders in genetically susceptible hosts.
\end{abstract}

Keywords: alzheimer's disease; gut microbiota; NLRP3 inflammasome; amyloid-beta; neuroinflammation

\section{Introduction}

Alzheimer's disease (AD) is a progressive neurodegenerative disorder that accounts for the majority of dementia cases. An estimated 50 million people are living with dementia globally, and it is projected to approximately triple by 2050 [1]. As the population ages, AD will be expected to impose substantial health, social, and economic burdens on societies. 
Currently, there is no effective treatment that can prevent or slow the progression of $\mathrm{AD}$. Several theories have been proposed to address the pathogenesis of AD, including neuronal loss, amyloid aggregation, synaptic dysfunction, tau hyperphosphorylation, oxidative stress, and inflammation [2-4]. Despite comprehensive research efforts, the molecular mechanisms underlying the onset and progression of $\mathrm{AD}$ in the aged population remain unclear. Emerging evidence from preclinical and clinical research suggests that gut microbiota may influence the pathogenic processes of several neurological diseases [5-9]. The alteration in gut microbiota composition could jeopardize host immune responses and promote the development of several neurological disorders including AD [10,11]. Thus, there is an unmet need to understand how alterations in the gut microbiota can be associated with $\mathrm{AD}$ pathogenesis.

The human gastrointestinal (GI) tract is populated by trillions of microbes that influence human physiology, synaptic function, immune function, gut barrier function, and host behavior, including cognition $[10,12-14]$. The gut microbiota can bidirectionally interplay with the central nervous system (CNS) through neuro-immuno-endocrinal signals which is termed the "gut-brain axis" [15]. Several neurotransmitters and metabolites, neurotrophic factors, and short-chain fatty acids (SCFAs) regulate several signaling pathways that in turn influence behavior, learning and memory, neuroinflammation, and neurodegeneration [16-18]. Although alterations in the gut microbiota composition have been documented in several gastrointestinal and metabolic diseases [19-21], the role of gut microbiota in neurodegenerative diseases, particularly $\mathrm{AD}$, have only recently been recognized, even though the gut is often referred as the "second brain". The composition and biodiversity of the gut microbiota of $\mathrm{AD}$ patients differ from those of healthy individuals [6,7]. Consistently, the gut microbiota composition of mouse models of AD is different from their control mice $[9,22,23]$. The gut microbiota composition changes with age in humans, with elderly people presenting a different profile from that of healthy adults [24]. Furthermore, several past studies have demonstrated that altered microbial composition could influence AD-related neuropathology and cognitive function $[7,9,25]$. Interestingly, manipulation of the gut microbiota effectively altered cognitive decline both in rodents and humans $[26,27]$. These findings strongly support the notion that alterations in gut microbiota composition may influence pathways toward neural damage and memory deficits in $\mathrm{AD}$, whereas the introduction of "eubiotic" (normal) microbes or probiotics may prevent $\mathrm{AD}$ progression. Although these studies support the role of gut microbiota in influencing the disease condition, a targeted mechanistic link between gut microbiota and $\mathrm{AD}$-associated neuroinflammation is lacking.

There is growing evidence supporting the role of a microbiota-gut-inflammasomebrain axis in neurodegenerative diseases [28-30]. Several studies have demonstrated that microbiota influence peripheral inflammatory response, which, in turn, could contribute to neuroinflammation and neurodegeneration [9,30-32]. NOD-like receptor protein 3 (NLRP3) inflammasome plays a significant role in both coordinating the host physiology and regulating the peripheral and central inflammatory responses in neurological diseases $[31,33,34]$. Upon sensing microbial or danger-associated molecular stimuli, the pyrin domain of NLRP3 interacts with the pyrin domain of the apoptosis-associated speck-like protein containing a caspase activating recruitment domain (ASC) to initiate the formation of the inflammasome complex, which consists of NLRP3, ASC, and procaspase-1 [30,35]. The activation of the inflammasome complex promotes the secretion of the proinflammatory cytokines interleukin (IL)-1 $\beta$ and IL-18 and induces pyroptosis [36]. However, there is currently insufficient evidence to link changes in the gut microbiota with the gut-microbialinflammasome-brain axis in AD. In the present study, we sought to examine how changes in gut microbiota influence peripheral NLRP3 inflammasome, which in turn, might trigger neuroinflammation during disease progression using a transgenic mouse model of $\mathrm{AD}$ harboring five familial AD-related mutations (5xFAD). We provide compelling evidence demonstrating that gut dysbiosis occurs in young and old 5xFAD mice, associated with increased NLRP3 inflammasome in the brain. The significance of gut microbiota is emerging 
in the AD field and our study contributes to this growing body of evidence for microbial roles in AD pathogenesis that may provide new avenues to not only better understand AD pathophysiology but also lead to the development of novel microbiome-based therapies.

\section{Materials and Methods}

\subsection{Mice and Brain Tissues}

The mouse colony was established and sustained by periodically breeding male B6SJLF1/J wild-type animals with female hemizygous 5xFAD mice. All founders were initially purchased from the Jackson laboratory (stocks \#100012 and \#006554, respectively). The 5xFAD animals carry mutant human transgenes harboring two mutations in presenilin 1 (PSEN1; M146L and L286V) and three others in the amyloid precursor protein (APP; Swedish mutation KM670/671NL, Florida mutation I716V, London mutation V717I). As the two transgenes translocate together, the offspring either expresses both transgenes (5xFAD animals) or none of them (non-transgenic animals). Only male mice were used in the present experiments, preventing possible sex differences in gene and protein expressions. All mouse experiments were performed in accordance with the National Institutes of Health's Guidelines for the Care and Use of Laboratory Animals and approved by the Institutional Animal Care and Use Committee (IACUC) at the University of Tennessee Health Science Center.

\subsection{Microbiome Analysis}

Colonic flushings of mice of each genotype and age were collected for microbiome analysis. DNA was extracted with TRIzol (Invitrogen, Carlsbad, CA, USA) as per the manufacturers' instructions. $16 \mathrm{~S}$ ribosomal RNA was analyzed by qPCR for different bacterial phyla or species using SYBR Green/ROX master mix (Qiagen) in an Applied Biosystems QuantStudio6 FlexReal-Time PCR instrument (Norwalk, CT, USA) as described in our published papers $[37,38]$. Primer sequences for $16 S$ ribosomal RNA genes for Bacteroidetes, Firmicutes, Bifidobacteria, and Lactobacillus were detailed in Table S1.

\subsection{Relative Quantitative Real-Time Reverse-Transcriptase PCR (RT-qPCR)}

Total RNA was isolated from the colon by using Triazole kit (Invitrogen, Carlsbad, CA, USA) and quantified using NanoDrop described in our previous publications $[39,40]$. RNA $(1.5 \mu \mathrm{g})$ was used for the generation of cDNAs using the ThermoScript RT-PCR system for first-strand synthesis (Invitrogen). Quantitative PCR (qPCR) reactions were performed using cDNA mix with primers and RT2 Real-Time SYBR Green/ROX master mix (Qiagen) in an Applied Biosystems QuantStudio 6 Flex Real-Time PCR instrument (Norwalk, CT, USA). The cycle parameters were $50{ }^{\circ} \mathrm{C}$ for $2 \mathrm{~min}$, one denaturation step at $95^{\circ} \mathrm{C}$ for $10 \mathrm{~min}$, and 40 cycles of denaturation at $95^{\circ} \mathrm{C}$ for $10 \mathrm{~s}$ followed by annealing and elongation at $60{ }^{\circ} \mathrm{C}$. Mouse GAPDH was used as an endogenous control. Relative changes in gene expression were analyzed using $2^{-\Delta \Delta C T}$ comparative method. The RT-qPCR primer sequences are listed in the Supplementary File (Table S1).

\subsection{Immunofluorescence Staining}

The immunofluorescent staining was performed as described previously by our group [40-42]. Briefly, mice were anesthetized with isoflurane, and the brain and colon tissues were removed quickly, postfixed in $4 \%$ paraformaldehyde solution, and cryoprotected with $30 \%$ sucrose in $0.1 \mathrm{M}$ phosphate-buffered saline (PBS) at $4{ }^{\circ} \mathrm{C}$ for $48 \mathrm{~h}$. Brain tissue was sectioned on a cryostat at $25 \mu \mathrm{m}$. Sections were washed with PBS followed by blocking with 5\% bovine serum albumin (BSA; Sigma Aldrich \# A7906) and 0.3\% Triton X-100. Brain sections were incubated overnight with monoclonal mouse NLRP3 (1:100; Adipogen \#AG-20B-0014-C100), glial fibrillary acidic protein (GFAP; 1:500 polyclonal rabbit; Abcam \#AB5804), and ionized calcium-binding adaptor molecule 1 (1:500; Iba-1; Wako). One of the following fluorescent secondary antibodies was used: Alexa Fluor 555 anti-rabbit, Alexa Fluor 488 anti-mouse, Alexa Fluor 488 anti-rabbit, or Alexa Fluor 555 anti-mouse (1:500, 
Life technologies, Grand Island, NY, USA). These sections were then washed and mounted using 4',6-diamidino-2-phenylindole medium (DAPI, Vector laboratories). Images were captured with a Zeiss 710 laser scanning confocal microscope (Carl Zeiss GmbH, Jena, Germany) using a 40X oil objective with a total magnification of 400X. All images for tissue samples from different groups were collected and processed under identical conditions of laser, gain, and magnification.

Immunofluorescence staining in the colon was performed as described previously $[38,40]$. Colon sections were examined for components of the inflammasome (NLRP3, ASC, and caspase-1), F-actin, tight junction (TJ) proteins occludin and ZO1, and adherens junction (AJ) proteins E-cadherin, and $\beta$-catenin by confocal microscopy as described previously. Cryosections of the distal colon (10 $\mu \mathrm{m}$ thickness) were fixed in the acetone-methanol mixture (1:1) at $20^{\circ} \mathrm{C}$ for $2 \mathrm{~min}$ and rehydrated in PBS. Sections were permeabilized with $0.3 \%$ Triton X-100 in PBS for $15 \mathrm{~min}$ and blocked with 5\% non-fat milk in PBST for $1 \mathrm{~h}$ at room temperature. Sections were then incubated with primary antibodies for $2 \mathrm{~h}$ : rabbit polyclonal anti-ZO1, or mouse anti-occludin antibodies (BD Biosciences; San Jose, CA, USA), rabbit anti- $\beta$-catenin, or mouse monoclonal anti-E-cadherin antibodies (Thermo Fisher Scientific, Waltham, MA, USA); or NLRP3 (Adipogen); ASC (\#AG-25B-0006-C100, Adipogen); or caspase-1 (\# sc-514; Santacruz; Dallas, TX, USA), followed by incubation with appropriate secondary antibodies (1:100 dilution; Life technologies, Grand Island, NY, USA) for $1 \mathrm{~h}$. Sections were coverslipped in mounting media with DAPI (ThermoFisher Scientific, Waltham, MA, USA). Images were captured with a Zeiss 710 laser scanning confocal microscope using a 20X with a total magnification of 200X. Immunofluorescence staining intensity was quantified by NIH Image J software (NIH, Bethesda, MD, USA) using three different fields per section of each mouse in the distal colon by an investigator blinded to the group assignment.

\subsection{ELISA}

Brain and colon tissues from the mice of each genotype and age were homogenized in a lysis buffer containing Halt ${ }^{\mathrm{TM}}$ protease and phosphatase inhibitor cocktail. A Sandwich ELISA Kit (R\&D system; Minneapolis, MN, USA) was used to quantify IL-1 $\beta$ levels in the hippocampus and colon tissues of 5xFAD and non-transgenic mice according to the manufacturers' instructions.

\subsection{Western Blot Analyses}

Brain and gut tissues were collected, flash-frozen, and stored at $-80^{\circ} \mathrm{C}$. Methods for SDS-PAGE electrophoresis and Western blotting were adapted from our previous work [43]. The following primary antibodies were selected: mouse anti-NLRP3 (\#AG20B-0014-C100; Adipogen, San Diego, CA, USA), rabbit anti-Caspase-1 (\#A0964; Abclonal, Woburn, MA, USA), or mouse anti-GAPDH (\#AM4300; ThermoFisher Scientific, Waltham, MA, USA). Donkey anti-mouse or goat anti-rabbit HRP-labeled IgGs (Vector Laboratories, Burlingame, CA, USA) were used as secondary antibodies. Bands were detected by enhanced chemiluminescence using the SuperSignal ${ }^{\mathrm{TM}}$ West Femto substrate (ThermoFisher Scientific, Waltham, MA, USA). Membranes were imaged with the Odyssey Fc imaging system (Li-Cor, Lincoln, NE, USA). Signal density was quantified using the complementary software, Image Studio Lite (Li-Cor, Lincoln NE, USA), with the relative expression of NLRP3 and Caspase-1, normalized to endogenous GAPDH levels.

\subsection{Statistical Analysis}

Two-way analysis of variance (ANOVA) was used to determine the effects of genotype and age on biochemical and morphological measures using GraphPad Prism 8 software (GraphPad Software, La Jolla, CA, USA). Values of $p<0.05$ were considered statistically significant, and data are expressed as mean \pm SEM. 


\section{Results}

\subsection{Altered Microbiome Composition in the Gut of Young and Old 5xFAD Mice}

To test the hypothesis that gut microbiota play an important role in AD pathology, we first compared the changes in gut microbiota signature in the fecal samples of age-matched 5xFAD mice and their control littermates. We found significantly altered expression of gut microbiota composition including Firmicutes, Bacteroidetes, Bifidobacteria, and Lactobacillus in colonic flushing of young ( 5 months) and aged (15 months) 5xFAD mice compared to non-transgenic (non-Tg) mice (Figure 1A-F). There was significant effect of age $\left(\mathrm{F}_{1,22}=26.74, p=0.0001\right)$ and genotype $\left(\mathrm{F}_{1,22}=19.08, p=0.0002\right)$ on Firmicutes, but no age ${ }^{*}$ genotype interaction $\left(\mathrm{F}_{1,22}=3.90, p=0.06\right)$ (Figure 1A). There was a significant effect of age $\left(\mathrm{F}_{1,22}=16.92, p=0.0005\right)$ and genotype $\left(\mathrm{F}_{1,22}=36.36, p<0.0001\right)$ and an age ${ }^{*}$ genotype interaction $\left(\mathrm{F}_{1,22}=13.44, p=0.0014\right)$ on the Bacteroidetes population (Figure 1B). For Bifidobacteria (Figure 1C), there was an overall effect of age $\left(\mathrm{F}_{1,22}=22.13, p=0.0001\right)$ and genotype $\left(\mathrm{F}_{1,22}=40.22, p<0.0001\right)$ but no significant age ${ }^{*}$ genotype interaction $\left(\mathrm{F}_{1,22}=1.832\right.$, $p=0.189)$. Similarly, there was a significant effect of age $\left(\mathrm{F}_{1,22}=12.64, p=0.0018\right)$ and genotype $\left(\mathrm{F}_{1,22}=19.49, p=0.0002\right)$ and an age ${ }^{*}$ genotype interaction $\left(\mathrm{F}_{1,22}=6.493, p=0.018\right)$ on the Bifidobacterium bifidum strain level abundance (Figure 1D). There were significant effects of age $\left(\mathrm{F}_{1,22}=52.75, p<0.0001\right)$ and genotype $\left(\mathrm{F}_{1,22}=48.60, p<0.0001\right)$ and a significant age ${ }^{*}$ genotype interaction $\left(\mathrm{F}_{1,22}=48.06, p<0.0001\right)$ on Lactobacillus (Figure 1E). Similarly, the Firmicutes to Bacteroidetes ratio ( $\mathrm{F} / \mathrm{B}$ ratio) was also significantly reduced in young and old 5xFAD mice (Figure $1 F)$. We found significant effects of age $\left(\mathrm{F}_{1,22}=6.98, p=0.014\right)$ and genotype $\left(\mathrm{F}_{1,22}=6.86, p=0.015\right)$ but no significant effect of age ${ }^{*}$ genotype interaction $\left(\mathrm{F}_{1,22}=3.98, p=0.058\right)$ on $\mathrm{F} / \mathrm{B}$ ratio. Thus, our results support previous evidence that under conditions of neurodegeneration, the composition of gut microbiota is altered.
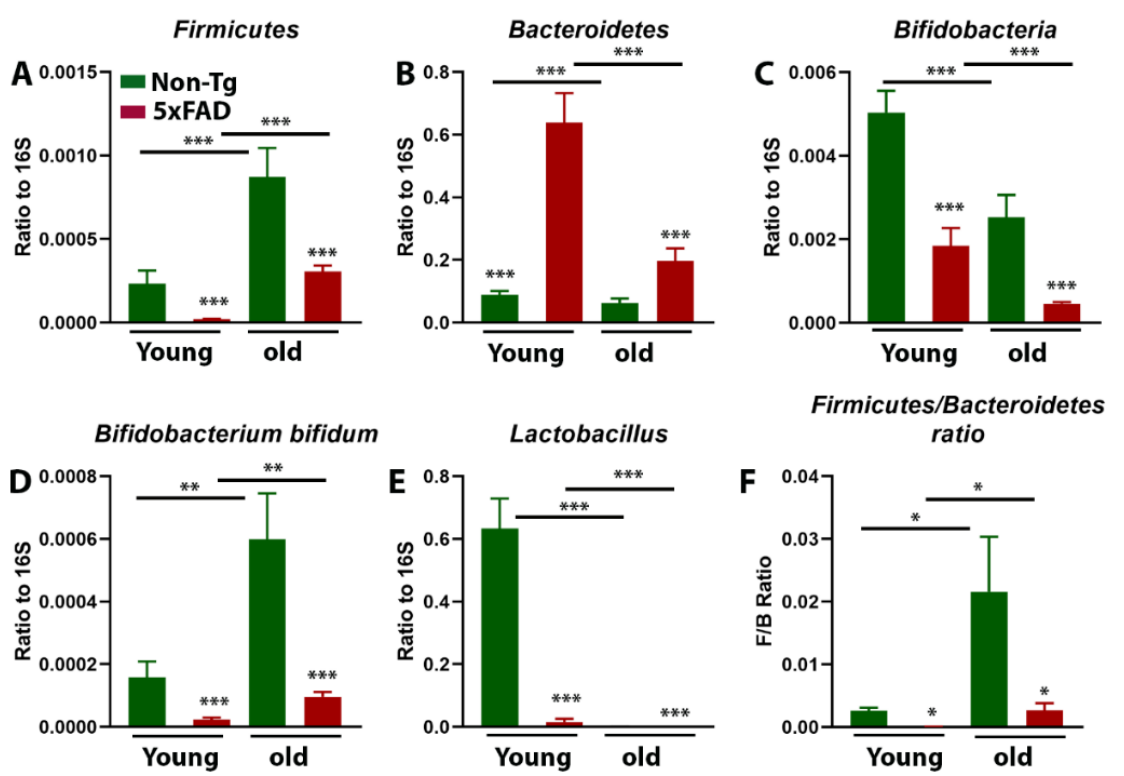

Figure 1. Age-dependent alteration in gut microbiota signature in 5xFAD mice. Firmicute (A), Bifidobacteria (C), Bifidobacterium bifidum (D), and Lactobacillus (E) were significantly depleted, while Bacteroidetes (B) were upregulated in colonic flushing in young (5-month) and old 5xFAD (15-month) mice compared to their age-matched control littermates. The F/B ratio is also altered in young and old 5xFAD mice compared to their age-matched non-transgenic (Non-Tg) mice (F). Values are expressed as means \pm SEM. $(\mathrm{N}=6-7 /$ group $) * p<0.05,{ }^{* *} p<0.01,{ }^{* * *} p<0.001$.

\subsection{Compromised Gut Barrier Function in 5xFAD Mice}

The tight junction (TJ) proteins, including zonula occludens (ZO), occludin, and claudins, play a crucial role in maintaining the integrity of the intestinal tight junction barrier. An imbalance or loss of these proteins leads to compromised barrier integrity 
and is linked with several pathological conditions [44,45]. Therefore, we sought to determine whether changes in gut microbiota composition can impair the integrity of the gut barrier. For this purpose, the expression levels of mRNA and proteins involved in the maintenance of gut barrier integrity were quantified by RT-qPCR and immunohistochemistry (Figure 2A-E). To determine the effect of AD condition on colonic epithelial TJ and $\mathrm{AJ}$ integrity, distal colon cryosections from young $5 \times \mathrm{FAD}$ and their age-matched non- $\mathrm{Tg}$ littermates were stained for TJ (occludin and ZO-1) and $\mathrm{AJ}$ (E-cadherin and $\beta$-catenin) proteins. The junctional distribution of occludin and ZO-1 was reduced (Figure 2A). Similarly, E-cadherin and $\beta$-catenin were also reduced in the distal colon of 5xFAD mice (Figure 2B). The mRNA expression levels for ZO-1, occludin, and $\beta$-catenin were markedly decreased in young and old $5 \times$ FAD mice compared to their non-Tg animals. There were significant effects of age $\left(\mathrm{F}_{1,12}=13.91, p=0.003\right)$ and genotype $\left(\mathrm{F}_{1,12}=26.54, p=0.0002\right)$ or the age ${ }^{*}$ genotype interaction $\left(\mathrm{F}_{1,12}=11.62, p=0.005\right)$ on $\mathrm{ZO}-1$ expression (Figure $2 \mathrm{C}$ ). There were significant effects of age $\left(\mathrm{F}_{1,12}=11.75, p=0.005\right)$ and genotype $\left(\mathrm{F}_{1,12}=46.66, p<0.0001\right)$ on occludin expression (Figure 2D). Similar to ZO-1 data, there were significant effects of age $\left(F_{1,12}=9.86, p=0.008\right)$, genotype $\left(F_{1,12}=73.42, p<0.0001\right)$, and age ${ }^{*}$ genotype interaction $\left(\mathrm{F}_{1,12}=9.915, p=0.0058\right)$ on $\beta$-catenin expression (Figure $2 \mathrm{E}$ ). Taken together, these data indicate that the changes in gut microbial composition favor gut barrier disruption in 5xFAD mice which may lead to peripheral inflammation.
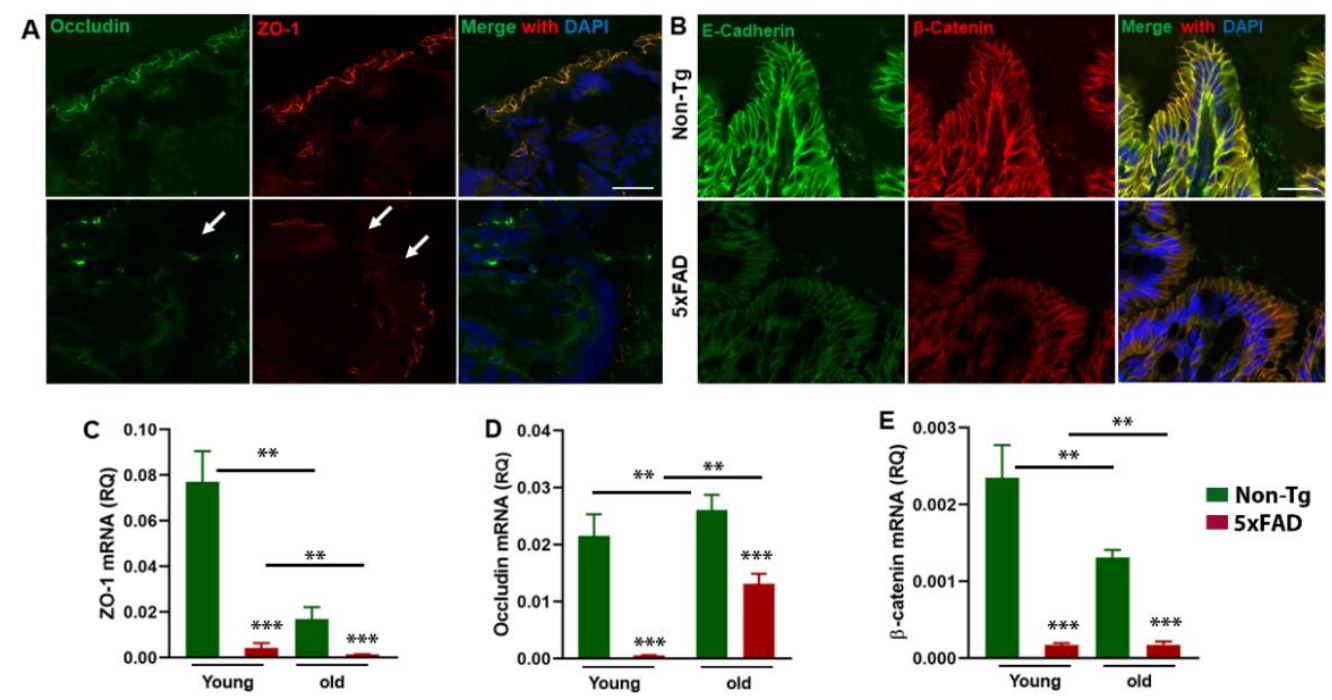

Figure 2. Compromised gut barrier function in 5xFAD mice. The upper panel shows representative images of distal colon sections showing the disruption of tight junction proteins (ZO-1 (red), occludin (green)) and adheren junction proteins ( $\beta$-catenin (red), E-cadherin (green)) in young 5xFAD mice and their control littermates $(\mathbf{A}, \mathbf{B}) \mathrm{N}=3$ /group. The lower panel (C-E) shows RT-qPCR analysis of junction proteins ZO-1, occludin, and $\beta$-catenin in young and old 5xFAD mice and their age-matched control littermates. The mRNA expressions of ZO-1, $\beta$ - catenin, and occludin were significantly decreased in 5xFAD mice of both young and old ages. ( $\mathrm{N}=4$ /group). Values are expressed as means $\pm \mathrm{SEM} .{ }^{* *} p<<0.01,{ }^{* * *} p<<0.001$.

\subsection{Increased NLRP3 Inflammasome and ASC Activation in the Gut of 5xFAD Mice}

It has been documented that microbiota interact with NLRP3 inflammasome in the gut, and the NLRP3 inflammasome has been shown to be activated in several neurodegenerative diseases [46-48]. Moreover, previous studies have reported that peripheral inflammation may influence CNS neuroinflammation during neuropathological conditions $[27,49,50]$. To determine whether the altered gut microbiota composition was accompanied by the activation of peripheral NLRP3 inflammasome and ASC, we first analyzed the NLRP3 inflammasome activation in the colon of young and old 5xFAD mice by RT-qPCR, Western blot, and immunohistochemistry. We observed increased mRNA and protein expression of NLRP3 in the colon tissue of young and old 5xFAD mice (Figure 3A-E). Two-way ANOVA analysis revealed that 
there were significant effects of age $\left(\mathrm{F}_{1,12}=7.53, \mathrm{P}=0.017\right)$ and genotype $\left(\mathrm{F}_{1,12}=7.80, p=0.016\right)$ on NLRP3 mRNA expression (Figure 3C). Consistent with the mRNA data, our Western blot (Figure 3A,D) and immunohistochemistry data (Figure 3B,E) showed significantly increased expression of NLRP3 in the colon sections of young and old 5xFAD mice compared to their age-matched control littermates. There were significant effects of age $\left(\mathrm{F}_{1,8}=24.31, p=0.001\right)$ and genotype $\left(\mathrm{F}_{1,8}=71.59, p<0.0001\right)$ on NLRP3 immunoreactivity. There was a larger effect of genotype on NLRP3 immunoreactivity than age. Similar to NLRP3 data, a higher expression of ASC (Figure 4A-C) was observed in the colon tissue of young and old 5xFAD as assayed by RT-qPCR and immunohistochemistry. Based on the two-way ANOVA analysis, there was a significant effect of genotype $\left(\mathrm{F}_{1,12}=27.67, p=0.002\right)$ but not age $\left(\mathrm{F}_{1,12}=1.614\right.$, $p=0.228$ ) on ASC mRNA expression. On the other hand, there were significant effects of age $\left(\mathrm{F}_{1,8}=9.22, p=0.016\right)$ and genotype $\left(\mathrm{F}_{1,8}=50.86, p<0.0001\right)$ on ASC immunoreactivity. These data indicate that the elevated expression of NLRP3 in the colon of 5xFAD mice is an important trigger for ASC recruitment and subsequent "downstream" activation of proinflammatory events, and gut microbiota could be a possible regulator of NLRP3 activation and inflammasome-mediated peripheral inflammation.
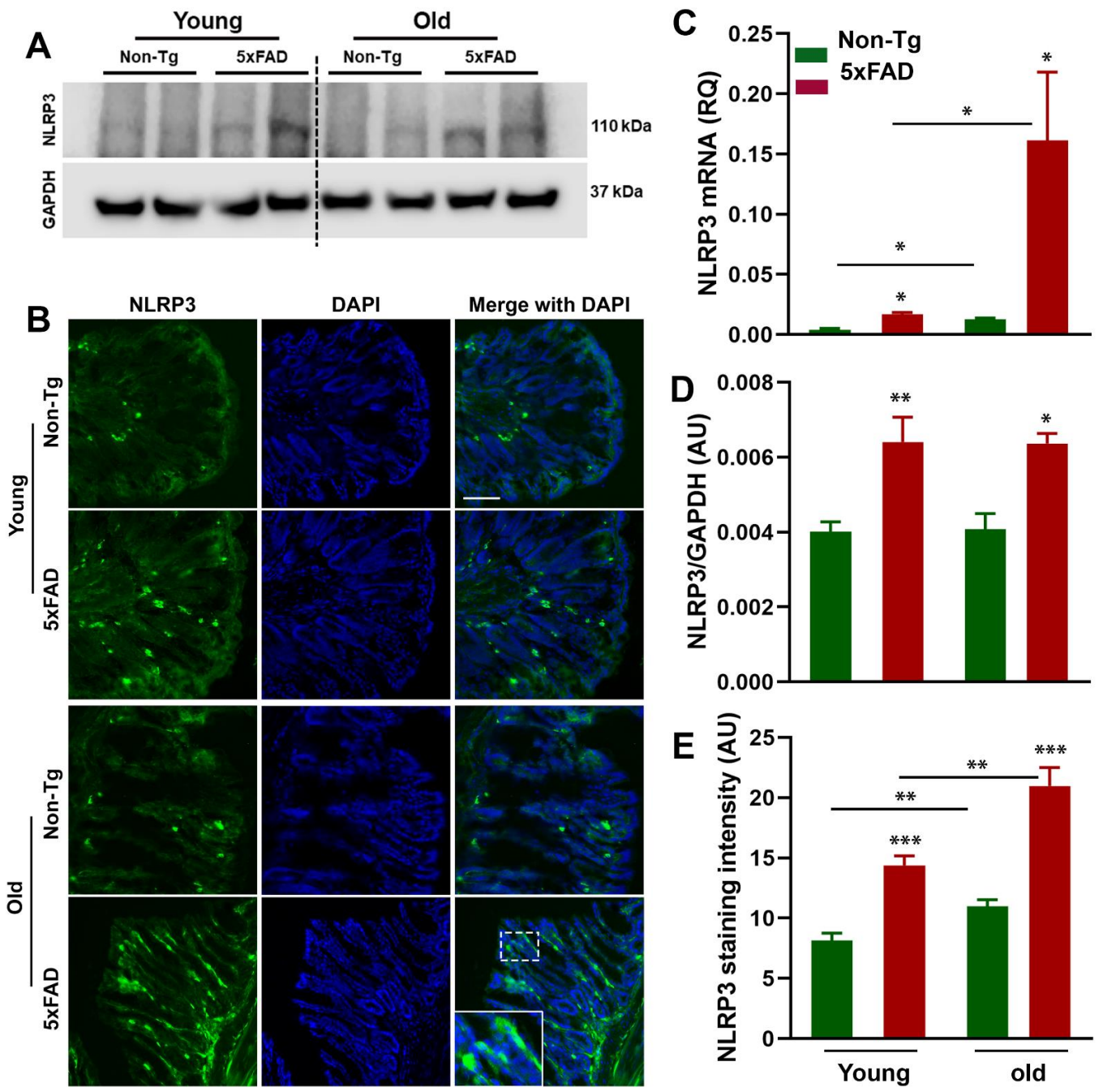

Figure 3. Age-dependent increased NLRP3 in the gut of 5xFAD mice. The expression levels of NLRP3 were determined by RT-qPCR ( $\mathrm{N}=4$ /group), Western blot ( $\mathrm{N}=3$ /group), and immunofluorescence ( $\mathrm{N}=3$ /group) in the colon of mice of each genotype and age (A-E). Western blot analysis of NLRP3 levels in the colon tissue of young and old Non-Tg and 5xFAD mice (A,D). The lower left panel shows representative fluorescent images of NLRP3 in colon (B). The right panel shows mRNA expression of NLRP3 (C) and quantitative analysis of NLRP3 (E) immunofluorescence. Values are expressed as means \pm SEM. ${ }^{*} p<0.05,{ }^{* *} p<0.01,{ }^{* * *} p<0.001$. Scale bar $=100 \mu \mathrm{m}$. 

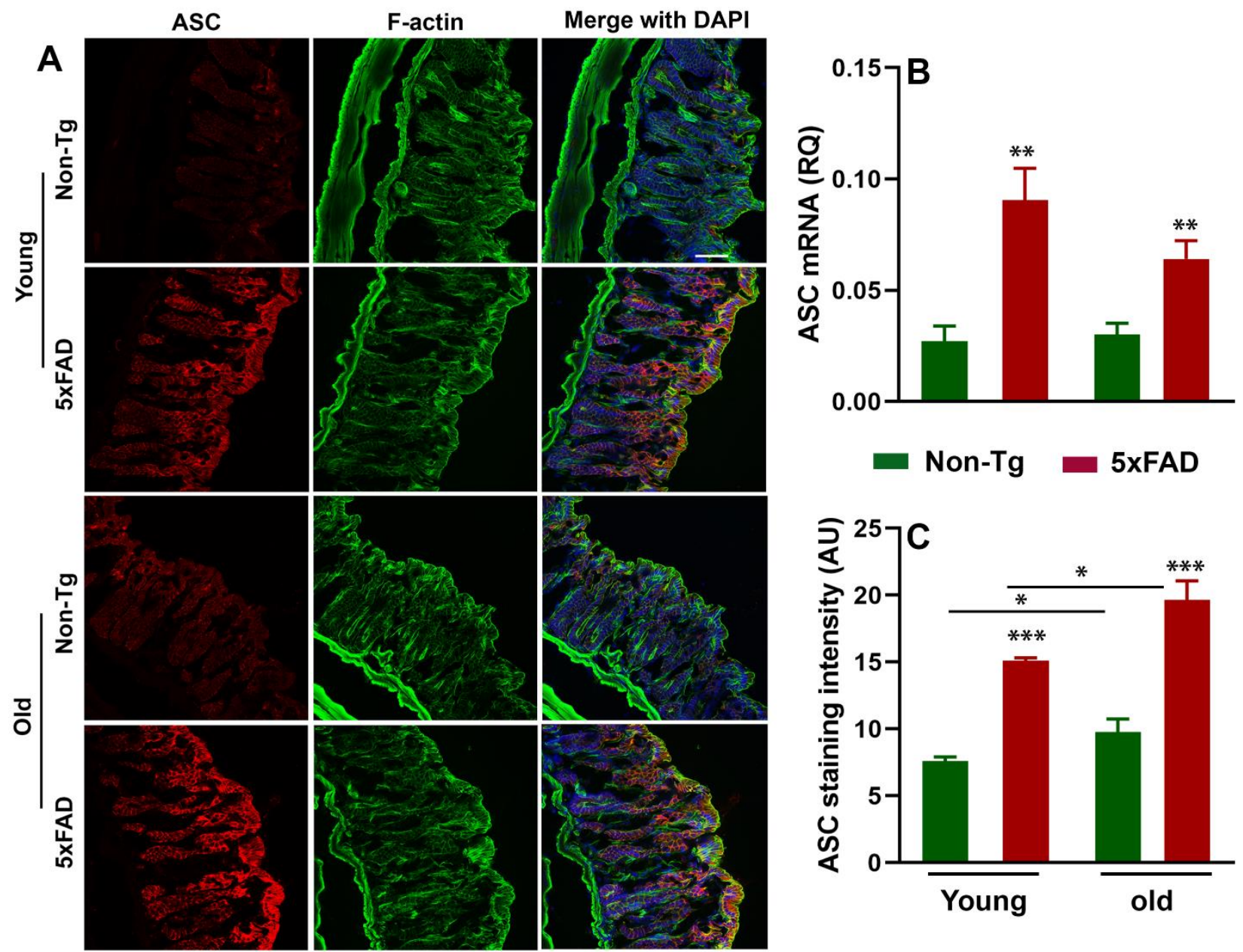

Figure 4. Age-dependent increased apoptosis-associated speck-like protein containing a caspase activating recruitment domain (ASC) in the gut of 5xFAD mice. The left panel shows representative fluorescent images of ASC colocalized with F-actin in the colon sections of young and old Non-Tg and 5xFAD mice (A). The right panel shows mRNA expression of ASC and quantitative analysis of ASC fluorescent intensity, respectively $(\mathbf{B}, \mathbf{C})$. Values are expressed as means \pm SEM. $\mathrm{N}=3$ $=4$ /group. ${ }^{*} p<0.05,{ }^{* *} p<0.01,{ }^{* * *} p<0.001$. Scale bar $=100 \mu \mathrm{m}$.

\subsection{Caspase-1-Induced Inflammation in the Gut of 5xFAD Mice}

NLRP3 activation triggers the formation of inflammasome via the self-oligomerization and the recruitment of adopter protein ASC and caspase-1, facilitating robust immune responses including the secretion of proinflammatory cytokines and pyroptosis [36,51]. Therefore, we investigated whether increased NLRP3 and ASC expression are positively correlated with caspase- 1 mediated inflammatory response in the gut of the young and old 5xFAD mice. Our immunohistochemistry and Western blot data showed increased caspase1 activation in the gut of $5 \times$ FAD mice compared to their age-matched non-transgenic littermates (Figure 5A-D). There was a robust effect of age $\left(\mathrm{F}_{1,8}=64.14, p<0.0001\right)$ and genotype $\left(\mathrm{F}_{1,8}=115.4, p<0.0001\right)$ on caspase-1 immunoreactivity. Given that immunohistochemistry did not differentiate procaspase 1 and cleaved caspase- 1 expression, we quantified cleaved caspase- 1 by Western blot. We observed increased cleaved caspase-1 which was more pronounced in aged 5xFAD mice (Figure 5C,D). It has been well documented that inflammasome formation caused the production of proinflammatory cytokine and pyroptosis [51]. Here, we sought to determine whether increased NLRP3 activation and subsequent inflammasome formation cause pyroptosis and IL- $1 \beta$ production in the colon tissue of 5xFAD mice. For this purpose, we examined gasdermine-D, a marker of pyroptosis and IL- $1 \beta$ production in the colon tissues of $5 x F A D$ mice and their age-matched 
control littermates, by RT-qPCR and ELISA methods. There was a significant effect of age $\left(\mathrm{F}_{1,16}=5.05, p=0.039\right)$ and genotype $\left(\mathrm{F}_{1,16}=63.34, p<0.0001\right)$ on the mRNA expression level of gasdermin-D (Figure $5 \mathrm{E}$ ). Next, we observed a significant difference in both RNA and protein levels of IL-1 $\beta$ in young and old $5 \times$ FAD mice compared to their agematched control littermates (Figure $5 \mathrm{~F}, \mathrm{G})$. There was a significant effect of age $\left(\mathrm{F}_{1,12}=30.22\right.$, $p=0.0001)$ and genotype $\left(\mathrm{F}_{1,12}=8.62, p=0.012\right)$ on the mRNA expression level of IL-1 $\beta$. In terms of IL-1 $\beta$ protein level, there was a significant effect of genotype $\left(\mathrm{F}_{1,22}=7.12\right.$, $p=0.014)$ but not of age $\left(\mathrm{F}_{1,22}=3.02, p=0.096\right)$ or an age genotype interaction $\left(\mathrm{F}_{1,22}=0.12\right.$, $p=0.730$ ). We speculate that NLRP3 activation further induces the upregulation of ASC with an increased expression of cleaved caspase-1, which further leads to the activation of the inflammatory response and pyroptosis.
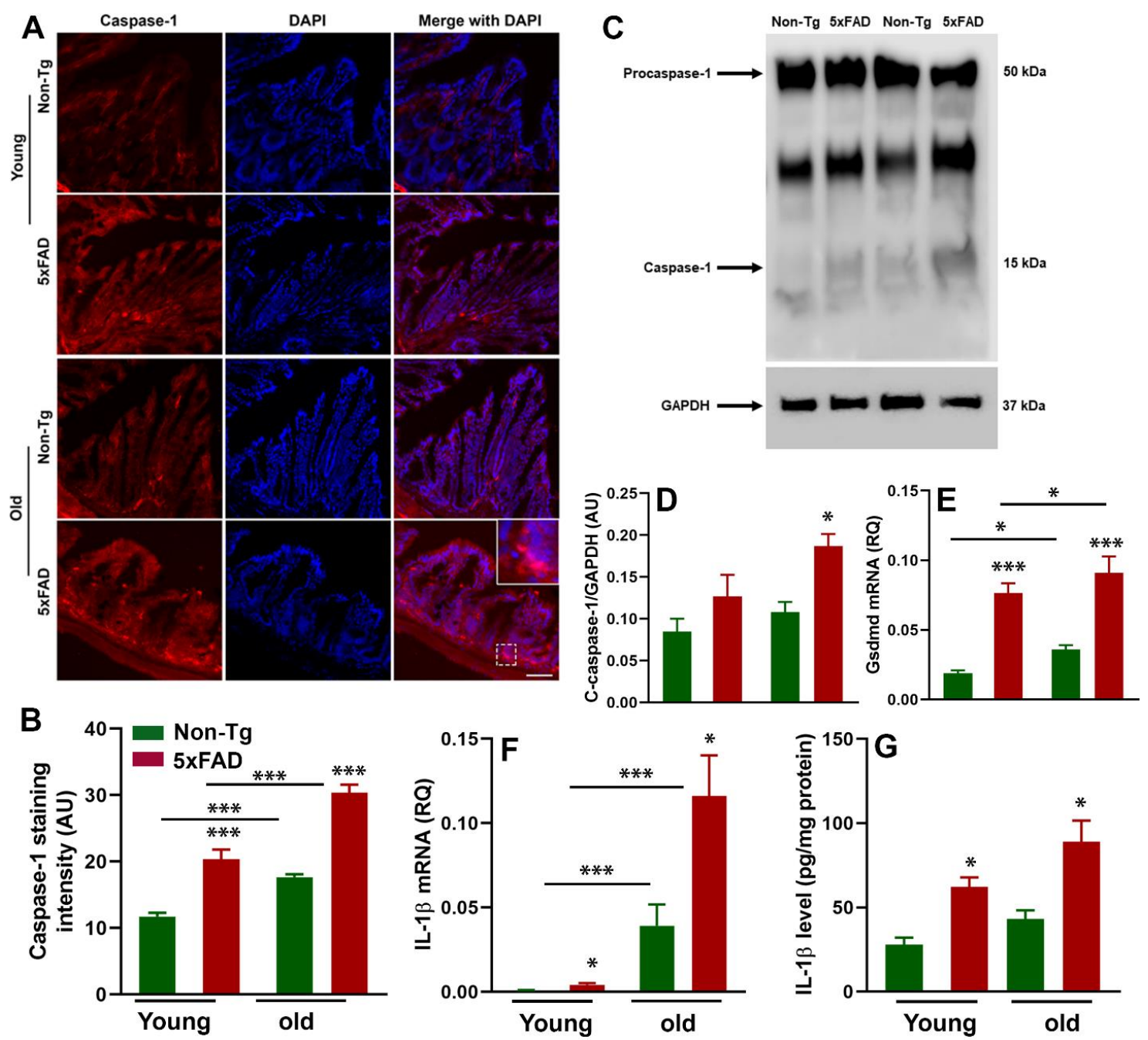

Figure 5. Age-dependent increased caspase- 1 maturation, gasdermin-D, and IL-1 $\beta$ production in the gut of 5xFAD mice. Caspase- 1 was quantified by immunofluorescence and Western blot ( $\mathrm{N}=3$ /group). The left panel shows representative fluorescent confocal images of caspase- 1 and the quantification of their intensity in the colon sections of young and old 5xFAD mice and their age-matched control littermates $(\mathbf{A}, \mathbf{B})(\mathrm{N}=3$ /group; scale bar $=100 \mu \mathrm{m})$. The upper right panel shows Western blot analysis of cleaved caspase-1 levels in the colon of young and old 5xFAD mice and their age-matched control littermates (C,D). The middle right panel shows gasdermin-D mRNA expression levels in the colon of young and aged 5xFAD mice bt RT-qPCR (E). The right lower panels show quantification of interleukin (IL)- $1 \beta$, by RT-qPCR (N = 4 /group) and enzyme-linked immunosorbent assay ( $N=6$ /group) $(F, G)$, respectively, in the colon homogenates from mice of each genotype and age. Values are expressed as means \pm SEM. ${ }^{*} p<0.05,{ }^{* * *} p<0.001$. 


\subsection{Increased NLRP3 Inflammasome is Associated with Neuroinflammation in the Brains of 5xFAD Mice}

Increased expression of NLRP3 has been documented in the blood and brain samples of cognitively impaired patients, suggesting peripheral NLRP3 inflammasome has a pathogenic role in $\mathrm{AD}[52,53]$. We analyzed NLRP3, a component of the inflammasome, by Western blot in the hippocampus of young and aged 5xFAD mice and their non-transgenic littermate. We observed age-dependent increased NLRP3 levels in the hippocampus of 5xFAD mice as compared to non-transgenics. (Figure 6A). There were significant effects on age $\left(\mathrm{F}_{1,8}=6.68, p=0.032\right)$ and genotype $\left(\mathrm{F}_{1,8}=45.83, p=0.0001\right)$, but no effect of age $e^{*}$ genotype interaction $\left(\mathrm{F}_{1,8}=1.833, p=0.213\right)$, on NLRP3 levels in the hippocampus of 5xFAD mice and their non-transgenic littermates. There is abundant evidence that microglia and astrocytes are activated in the brains of AD patients and secrete various pro-inflammatory cytokines that further exacerbate neurodegeneration [54,55]. Here, we examined the expression of astrocytes and microglia positive for NLRP3 in young and old 5xFAD mice and their control littermates (Figure 6C,D). 5xFAD mice contained more activated GFAP (green fluorescence) along with NLRP3 (red fluorescence)-positive astrocytes (Figure 6C). Additionally, increased activated Iba1 (red fluorescence) and NLRP3 (green fluorescence)-positive microglia (Figure 6D) with enhanced expression of NLRP3 was observed in 5xFAD mice as compared to non-transgenics. The NLRP3 inflammasome located in microglia and astrocytes triggers the production of proinflammatory cytokines such as IL-1 $\beta$ and induces pyroptotic cell death. Interestingly, increased NLRP3 activation in glial cells is positively correlated with the overproduction of IL- $1 \beta$ in the hippocampus of young and old 5xFAD mice compared to age-matched control littermates (Figure 6B). These data indicate that the elevated expression of NLRP3 in astrocytes and microglia in 5xFAD mice is an important trigger for subsequent downstream activation of the inflammatory response which may ultimately lead to AD-related neuropathology and memory loss.
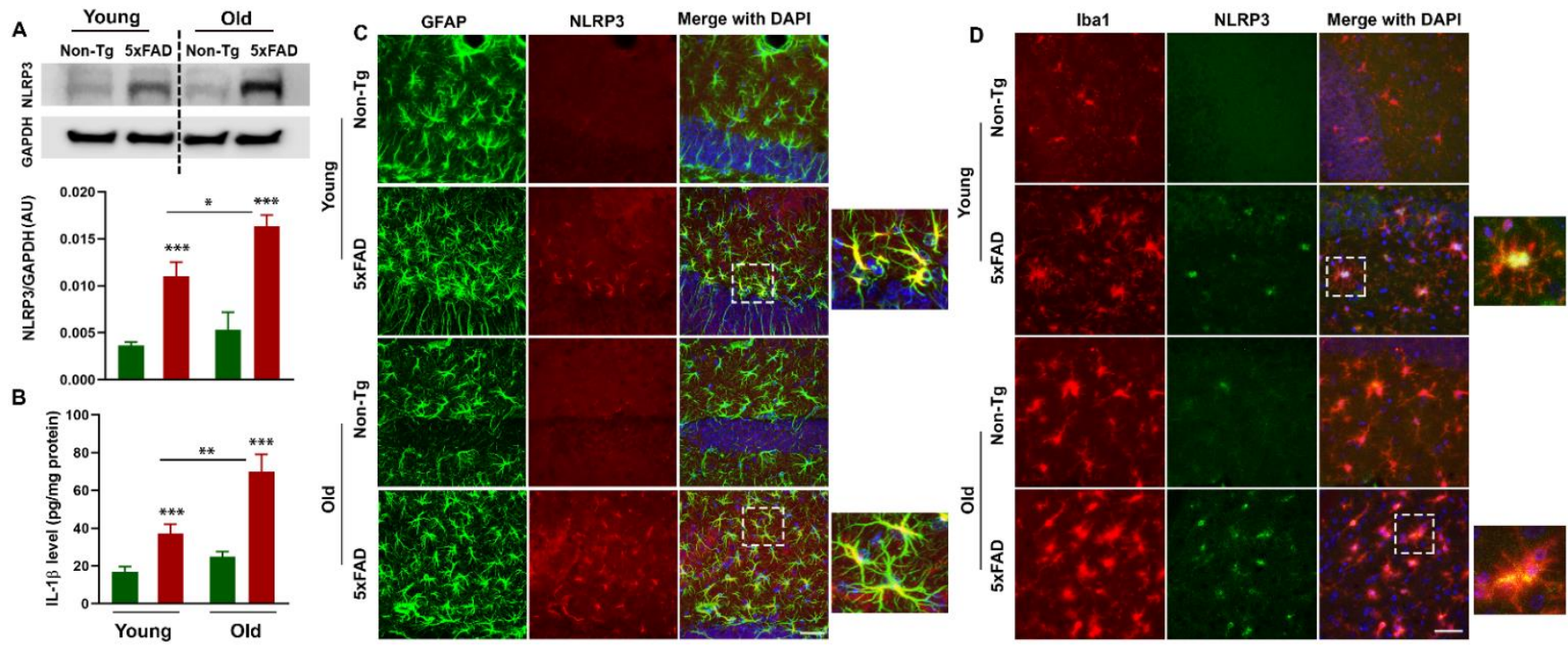

Figure 6. Age-dependent increased NLRP3 inflammasome-mediated neuroinflammation in the brains of 5xFAD mice. The left panel shows Western blot analysis of NLRP3 levels in the hippocampus of young and old 5xFAD mice and their age-matched control littermates ( $\mathrm{N}=3$ /group) (A). The left lower panel shows quantification of interleukin (IL)- $1 \beta, \mathrm{by}$ ELISA $(\mathbf{B})$ in the hippocampus of mice of each genotype and age. The values are expressed as mean $\pm \mathrm{SEM} .{ }^{*} p<0.05$ (N $=$ 6 /group). The middle and right panels show representative confocal images of brain sections showing the colocalization of NLRP3 with astrocytic (glial fibrillary acidic protein (GFAP), green), and microglia (Iba1, red) markers (C,D). Concomitant expression of astrocytes and microglia with NLRP3 was more frequently observed in the hippocampus of young and old 5xFAD mice compared to control littermates. Scale bar $=50 \mu \mathrm{m}$. ( $\mathrm{N}=3$ /group). ${ }^{*} p<0.05,{ }^{* *} p<0.01,{ }^{* * *} p<0.001$. 


\section{Discussion}

Prior research has demonstrated neuroinflammation plays a fundamental role in the progression of Alzheimer's disease (AD). However, the role of peripheral inflammation, particularly originating from the gut, in AD progression is less well described. Growing evidence suggests that the dynamic changes in the gut microbiota may contribute to a broad range of neurological disorders through the release of metabolites, modulation of neuroimmune compartments, and activation of inflammatory pathways $[7,14,56,57]$. Among these pathways, studies showed that the gut-microbial-NLRP3 inflammasome activation plays a critical role in neuroinflammation and AD-related neuropathology. However, the nature of the mechanisms through which alterations in gut microbiota composition can influence neuroinflammation in $\mathrm{AD}$ is not known. In this study, we provided cogent mechanistic evidence supporting the role of gut dysbiosis in impairment of gut barrier function and activation of peripheral inflammation, which in turn may trigger neuroinflammation in a mouse model of AD. We specifically find that elevated Bacteroidetes with concurrent loss of protective bacteria, such as Bifidobacterium, are positively correlated with compromised gut barrier function and increased gut inflammasome activation in 5xFAD mice. We further report that increased peripheral inflammasome activation triggers NLRP3-mediated neuroinflammation in the brains of 5xFAD mice. The observation that the gut microbiota and peripheral inflammation promote neuroinflammation during neurodegenerative conditions is consistent with previous reports [30,57,58].

In our study, we chose the $5 x F A D$ transgenic mice because they demonstrate robust neuropathological alterations including $A \beta$ deposition (Figure 51 ) comparable to those observed in $\mathrm{AD}$ patients. To determine whether gut dysbiosis is associated with $\mathrm{AD}$, we examined the gut microbiota in fecal samples of young and old 5xFAD mice and their nontransgenic littermates. We found altered gut microbiota composition in the fecal samples of young and old 5xFAD mice as compared to their age-matched non-transgenic littermates. In particular, the relative abundance of Firmicutes, Bifidobacteria, and Lactobacillus is decreased while the relative abundance of Bacteroidetes is significantly increased in the fecal samples of 5xFAD mice. However, microbiota from 5xFAD and their control littermates showed notable differences across ages in the same genotype. Our findings are consistent with previous studies that showed significant alterations in the composition and biodiversity of the gut microbiota in preclinical AD models and AD patients $[6,7,9,59]$. For instance, Vogt et al. found a significant alteration in gut microbiota composition, including decreased Firmicutes, increased Bacteroidetes, and decreased Bifidobacterium in the fecal samples of AD patients, compared to the microbiota of healthy controls, suggesting AD is associated with changes in the gut microbiome [7]. Similar to this study, Zhuang and colleagues also found altered gut microbial composition in the fecal samples of AD patients compared to age- and sex-matched cognitively normal controls [6], suggesting the potential contribution of gut microbiota to AD pathogenesis. Consistent with human studies, Bäuerl et al. reported a significant shift in the gut microbiota composition during AD progression in an APP/PSS1 transgenic mouse model of $\mathrm{AD}$ [23]. Chen and coworkers found a significant alteration of the gut microbiota composition in two different mouse models of $\mathrm{AD}$ (5xFAD and $3 x \operatorname{Tg}$ mice), indicating the potential influence of gut microbiota in AD pathogenesis [60]. Contrary to a previous study [8], in our hands, the firmicutes and bacteroidetes ratio was significantly reduced in the fecal samples of 5xFAD mice compared to non-transgenic mice, presumably due to different age groups, diet, and environmental factors. Similarly, a study by Kim and coworkers demonstrated the altered composition of gut microbiota that are correlated with the loss of epithelial barrier integrity and chronic intestinal and systemic inflammation in mice with AD-related neuropathology [9]. In support of this idea, a study by Harach and coworkers showed that germ-free APPPS1-21 transgenic mice, expressing familial AD-linked APPSWE and PS1L166P transgenes, display more reduced $\mathrm{A} \beta$ deposition than conventional transgenic mice [61], indicating that gut microbiota influence the development of amyloid pathology. Consistent with this notion, a study by Lee et al. demonstrated that probiotic treatment modulates gut dysbiosis and gut barrier 
function and suppresses the accumulation of $A \beta$ plaques, gliosis, and cognitive deficits, suggesting that maintaining gut microbial homeostasis may have beneficial effects on $\mathrm{AD}$ [26]. Therefore, it is reasonable to infer that alterations in the gut microbial composition may lead to pathophysiological changes in the brain of 5xFAD mice.

Gut barrier function is critical for normal gut homeostasis, and a compromised gut barrier function is closely associated with the pathophysiology of gut inflammation [62,63]. Gut microbiota interact directly with the gut epithelial cells, which, together with the mucus layer, act as a barrier interposed between the luminal contents and the underlying neuroimmune compartments. Proteins associated with tight junction and adheren junction, such as zonula occludin ( $\mathrm{ZO})$, occludin, E-cadherin, and $\beta$-catenin, contribute to the formation of gut tight junction barrier that ensures the epithelial barrier integrity and regulate the paracellular permeability [64]. Gut microbiota and their metabolic products, such as short-chain fatty acids (SCFAs), regulate the integrity of the intestinal epithelial barrier [62]. Bacterial metabolites also act as epigenetic modifiers such as butyrate and influence barrier integrity and brain function. For instance, eubacterium rectale is known to produce butyric acid, a SCFA and has already been associated with cognitive decline [52,65]. Moreover, it has been reported that an altered gut microbiota composition can influence gut barrier dysfunction, which facilitates the translocation of gut bacteria-derived pathogens and toxins such as lipopolysaccharide (LPS) into the systemic circulation. Consistent with this notion, recent studies showed gut barrier dysfunction and increased gut permeability in mouse models of AD and dementia patients [66-68]. Moreover, the integrity of the epithelial gut barrier is reduced with aging and neurodegenerative conditions [69-71]. Consistent with these findings, our RT-qPCR and immunohistochemistry data showed a significantly reduced expression of tight and adheren junction proteins in the colon tissues of 5xFAD mice compared to their age-matched control littermates, suggesting compromised gut barrier function in $\mathrm{AD}$ condition. Our findings of compromised gut barrier function in a mouse model of $\mathrm{AD}$ are in good agreement with those studies which reported gut barrier dysfunction associated with altered microbial composition during neurodegenerative conditions [60,72]. Given that gut microbiota can influence the rearrangement of TJs which mediate gut permeability [73], dysbiosis observed in this study could drive increased gut barrier dysfunction observed in 5xFAD mice. Commensal bacteria and probiotics have been shown to enhance intestinal barrier integrity. For example, Lactobacillus plantarum and Bifidobacterium infantis enhance the intestinal barrier by increasing the expression of the protein associated with tight junctions [73]. On the contrary, the exotoxin of Bacteroides fragilis disrupts adherens junctions by cleavage of cell adhesion molecules such as Ecadherin [74]. These findings highlight the significance of gut microbiota in the maintenance of gut barrier function. We speculate that an imbalance in gut microbiota signature and compromised intestinal barrier structure may flare up into an overwhelming immune response in the gut milieu.

Although the role of the gut microbiome in neurodegenerative diseases is fairly well studied, the mechanisms of its involvement in neuroinflammation are less understood. Gut microbiota can contribute to inflammation in several ways, including direct inflammatory stimulation, the production of pro-inflammatory metabolites, and the loss of immune regulatory function $[10,75]$. It has been demonstrated that gut microbiota release a significant level of amyloids and LPS and trigger enteric and peripheral inflammatory responses, which, in turn, could contribute to neuroinflammation [26,76]. For instance, the plasma concentrations of LPS in AD patients and mouse models of AD are significantly higher than in their respective controls [26,77]. Interestingly, probiotic treatment suppresses LPS production and ameliorates inflammation and $A \beta$ deposition [26]. Besides, microbial products can directly activate circulating immune cells, which, in turn, infiltrate the CNS and alter brain physiology $[14,49,78]$. The aggregation of a large number of inflammatory mediators can further exacerbate glia activation and induce neural degeneration, ultimately impairing memory and cognitive functions. A study by Wang et al. demonstrated that changes in gut microbiota signature facilitate the infiltration of peripheral immune cells in the brain, 
resulting in enhanced microglial activation that contributes to $A \beta$ burden and cognitive impairment in mice [11]. Most of the innate immune responses are mediated by pattern recognition receptors such as Toll-like receptors (TLRs) or cytosolic NOD-like receptors (NLRs) that recognize the microbe-associated molecular patterns expressed by gut microbiota. NOD-like receptor protein 3 (NLRP3) inflammasome serves as an important player in both coordinating the host physiology and regulating the peripheral and central inflammatory responses in neurological diseases $[31,33,47]$. Upon activation, NLRP3 triggers the assembly of inflammasome via the self-oligomerization and the recruitment of adopter protein ASC and pro-caspase-1, facilitating robust immune responses including the secretion of proinflammatory cytokines and pyroptosis $[48,79]$. The activated NLRP3 inflammasome is a critical driver of neuroinflammation in $\mathrm{AD}$ as shown by several past studies $[48,80]$. In this context, there is growing amount of evidence supporting the occurrence of the dynamic interplay between the gut microbiota and the NLRP3 inflammasome, currently referred to as a microbiota-gut-inflammasome-brain axis, where gut microbiota modulate peripheral inflammatory pathways through inflammasome signaling that, in turn, contribute to and/or influence CNS neuroinflammation [29,30,34,52,58]. NLRP3 recognizes the microbe-associated molecular patterns expressed by gut microbiota, and changes in microbial composition are associated with increased levels of NLRP3 in the plasma of patients with cognitive impairment and brain amyloidosis [52]. Moreover, the microbial product LPS has also been reported to trigger NLRP3 inflammasome [81]. Direct evidence of microbiota-gut-inflammasome-brain axis comes from a study by Shen et al., which shows that fecal transplantation from AD patients in APP/PS1 transgenic mice induces the activation of gut NLRP3 inflammasome and the production of proinflammatory cytokines, which further aggravate neuroinflammation and cognitive deficits [30]. Interestingly, they further observed that the introduction of youthful microbiota alters the inflammatory response in the mouse intestinal and brain tissues. A study by Lowe and coworkers showed that the depletion of gut microbiota with an antibiotic cocktail influenced the inflammasome signaling in the intestine, circulation, and the brain [34], suggesting that the gut microbiota can influence the expression of inflammasome components elsewhere. Indeed, microbiota in NLRP3-deficient mice differ from those in wild-type animals [82]. Interestingly, fecal microbiota transplantation (FMT) from NLRP3-deficient mice significantly ameliorated depressive-like behavior and locomotor activities [83]. Therefore, it is conceivable that the changes in gut microbiota can influence neuroinflammation by activating the gut NLRP3 inflammasome and releasing inflammatory mediators. Compared to the findings from previous reports, our study further clarifies the correlation between gut microbiota and neuroinflammation in a transgenic model of AD. In the present study, we also found that 5xFAD mice exhibited age-dependent increased NLRP3 inflammation activation in the gut tissues along with increased expression levels of ASC,caspase-1, and gasdermin-D, which are positively correlated with increased production of proinflammatory cytokine IL-1 $\beta$. Interestingly, increased peripheral inflammasome activation is positively correlated with activated microglia and astrogliosis in the hippocampus of young and aged 5xFAD mice. Our findings are in agreement with previous studies that peripheral inflammation triggers a neuroinflammatory response, characterized by sustained glial activation with detrimental consequences for learning and memory in neurodegenerative condition [30,52,84-87], thus supporting the view that the gut-microbial inflammatory response might represent the earliest events of neuroinflammation in AD. In support of these studies, a recent study by Tjera et al. shows that systemic inflammation impairs microglia $A \beta$ clearance through NLRP3 inflammasome in a mouse model of AD [81], suggesting a contributory role of peripheral inflammation in the induction of NLRP3-driven neuroinflammation.

There are several limitations of this study. First, we have not utilized the whole genome shotgun sequencing method to identify the gut microbiota signature at species and strain levels that may account for AD-associated neuroinflammation. Therefore, further study is required to identify the specific gut microbes during $\mathrm{AD}$ onset and progression which may yield novel therapeutic and diagnostic biomarkers. Second, although we did 
see a change in NLRP3 inflammasome in the gut and the brain tissues of 5xFAD mice, it remains unknown whether the peripheral inflammasome is sufficient to influence AD-related neuropathology and cognitive function. These limitations encourage further works to clarify the mechanism of the microbiota-gut-inflammasome-brain axis and their functional impact on AD pathogenesis. In conclusion, our findings lead to the speculation that an original shift in gut microbiota signature alters the integrity of gut barrier function through the release of metabolites and triggers the pathological activation of the gut and subsequently brain inflammasome complexes, ultimately leading to exacerbated neuroinflammation in a mouse model of AD.

Supplementary Materials: The following are available online at https:/ / www.mdpi.com/article/ 10.3390/cells10040779/s1, Table S1: Mouse primers for qPCR and RT-qPCR and Figure S1: A $\beta$ deposition in the hippocampus of 5xFAD mice and their control littermates.

Author Contributions: P.K.S. carried out the microbiome analysis, RT-qPCR analysis, and performed gut immunohistochemistry experiments. D.F.D. carried out Western blot analysis and edited the manuscript. J.X. performed mice breeding and genotyping and edited the manuscript. J.F.P., R.R., and M.P.M. provided important intellectual insights and edited the manuscript. M.M.K. conceived the idea, designed the study, performed brain immunohistology, and wrote the manuscript. All authors have read and agreed to the published version of the manuscript.

Funding: This work was supported by the William and Ella Owens Medical Research Foundation (M.M.K.), NIH grants R03 NS114616 (M.M.K.), AA12307 (R.K.R.), U.S. Department of Veterans Affairs grant I01BX003014 (R.R.), and the Division of Rehabilitation Sciences, College of Health Professions, University of Tennessee Health Science Center.

Institutional Review Board Statement: Not applicable.

Informed Consent Statement: Not applicable.

Data Availability Statement: The data generated and analyzed in this study are available from the corresponding authors on reasonable request.

Conflicts of Interest: The authors declare no conflict of interest.

\section{References}

1. Zhang, F.; Zhong, R.J.; Cheng, C.; Li, S.; Le, W.D. New therapeutics beyond amyloid-beta and tau for the treatment of Alzheimer's disease. Acta Pharmacol. Sin. 2020. [CrossRef] [PubMed]

2. Serrano-Pozo, A.; Frosch, M.P.; Masliah, E.; Hyman, B.T. Neuropathological alterations in Alzheimer disease. Cold Spring Harb. Perspect. Med. 2011, 1, a006189. [CrossRef] [PubMed]

3. Kinney, J.W.; Bemiller, S.M.; Murtishaw, A.S.; Leisgang, A.M.; Salazar, A.M.; Lamb, B.T. Inflammation as a central mechanism in Alzheimer's disease. Alzheimers Dement. 2018, 4, 575-590. [CrossRef] [PubMed]

4. Du, X.; Wang, X.; Geng, M. Alzheimer's disease hypothesis and related therapies. Transl. Neurodegener. 2018, 7, 2. [CrossRef] [PubMed]

5. Tremlett, H.; Bauer, K.C.; Appel-Cresswell, S.; Finlay, B.B.; Waubant, E. The gut microbiome in human neurological disease: A review. Ann. Neurol. 2017, 81, 369-382. [CrossRef] [PubMed]

6. Zhuang, Z.Q.; Shen, L.L.; Li, W.W.; Fu, X.; Zeng, F.; Gui, L.; Lu, Y.; Cai, M.; Zhu, C.; Tan, Y.L.; et al. Gut Microbiota is Altered in Patients with Alzheimer's Disease. J. Alzheimers Dis. 2018, 63, 1337-1346. [CrossRef]

7. Vogt, N.M.; Kerby, R.L.; Dill-McFarland, K.A.; Harding, S.J.; Merluzzi, A.P.; Johnson, S.C.; Carlsson, C.M.; Asthana, S.; Zetterberg, H.; Blennow, K.; et al. Gut microbiome alterations in Alzheimer's disease. Sci. Rep. 2017, 7, 13537. [CrossRef]

8. Brandscheid, C.; Schuck, F.; Reinhardt, S.; Schafer, K.H.; Pietrzik, C.U.; Grimm, M.; Hartmann, T.; Schwiertz, A.; Endres, K. Altered Gut Microbiome Composition and Tryptic Activity of the 5xFAD Alzheimer's Mouse Model. J. Alzheimers Dis. 2017, 56, 775-788. [CrossRef]

9. Kim, M.S.; Kim, Y.; Choi, H.; Kim, W.; Park, S.; Lee, D.; Kim, D.K.; Kim, H.J.; Choi, H.; Hyun, D.W.; et al. Transfer of a healthy microbiota reduces amyloid and tau pathology in an Alzheimer's disease animal model. Gut 2020, 69, 283-294. [CrossRef]

10. Blander, J.M.; Longman, R.S.; Iliev, I.D.; Sonnenberg, G.F.; Artis, D. Regulation of inflammation by microbiota interactions with the host. Nat. Immunol. 2017, 18, 851-860. [CrossRef]

11. Wang, X.; Sun, G.; Feng, T.; Zhang, J.; Huang, X.; Wang, T.; Xie, Z.; Chu, X.; Yang, J.; Wang, H.; et al. Sodium oligomannate therapeutically remodels gut microbiota and suppresses gut bacterial amino acids-shaped neuroinflammation to inhibit Alzheimer's disease progression. Cell Res. 2019, 29, 787-803. [CrossRef] [PubMed] 
12. Sharon, G.; Sampson, T.R.; Geschwind, D.H.; Mazmanian, S.K. The Central Nervous System and the Gut Microbiome. Cell 2016, 167, 915-932. [CrossRef] [PubMed]

13. Diaz Heijtz, R.; Wang, S.; Anuar, F.; Qian, Y.; Bjorkholm, B.; Samuelsson, A.; Hibberd, M.L.; Forssberg, H.; Pettersson, S. Normal gut microbiota modulates brain development and behavior. Proc. Natl. Acad. Sci. USA 2011, 108, 3047-3052. [CrossRef] [PubMed]

14. Fung, T.C.; Olson, C.A.; Hsiao, E.Y. Interactions between the microbiota, immune and nervous systems in health and disease. Nat. Neurosci. 2017, 20, 145-155. [CrossRef] [PubMed]

15. Mayer, E.A.; Tillisch, K.; Gupta, A. Gut/brain axis and the microbiota. J. Clin. Investig. 2015, 125, 926-938. [CrossRef] [PubMed]

16. Mittal, R.; Debs, L.H.; Patel, A.P.; Nguyen, D.; Patel, K.; O'Connor, G.; Grati, M.; Mittal, J.; Yan, D.; Eshraghi, A.A.; et al. Neurotransmitters: The Critical Modulators Regulating Gut-Brain Axis. J. Cell Physiol 2017, 232, 2359-2372. [CrossRef]

17. Dalile, B.; Van Oudenhove, L.; Vervliet, B.; Verbeke, K. The role of short-chain fatty acids in microbiota-gut-brain communication. Nat. Rev. Gastroenterol. Hepatol. 2019, 16, 461-478. [CrossRef]

18. Chen, Y.; Fang, L.; Chen, S.; Zhou, H.; Fan, Y.; Lin, L.; Li, J.; Xu, J.; Chen, Y.; Ma, Y.; et al. Gut Microbiome Alterations Precede Cerebral Amyloidosis and Microglial Pathology in a Mouse Model of Alzheimer's Disease. Biomed. Res. Int. 2020, $2020,8456596$. [CrossRef] [PubMed]

19. Weingarden, A.R.; Vaughn, B.P. Intestinal microbiota, fecal microbiota transplantation, and inflammatory bowel disease. Gut Microbes 2017, 8, 238-252. [CrossRef] [PubMed]

20. Boulange, C.L.; Neves, A.L.; Chilloux, J.; Nicholson, J.K.; Dumas, M.E. Impact of the gut microbiota on inflammation, obesity, and metabolic disease. Genome Med. 2016, 8, 42. [CrossRef]

21. Franzosa, E.A.; Sirota-Madi, A.; Avila-Pacheco, J.; Fornelos, N.; Haiser, H.J.; Reinker, S.; Vatanen, T.; Hall, A.B.; Mallick, H.; McIver, L.J.; et al. Gut microbiome structure and metabolic activity in inflammatory bowel disease. Nat. Microbiol. 2019, 4, 293-305. [CrossRef] [PubMed]

22. Zhang, L.; Wang, Y.; Xiayu, X.; Shi, C.; Chen, W.; Song, N.; Fu, X.; Zhou, R.; Xu, Y.F.; Huang, L.; et al. Altered Gut Microbiota in a Mouse Model of Alzheimer's Disease. J. Alzheimers Dis. 2017, 60, 1241-1257. [CrossRef]

23. Bauerl, C.; Collado, M.C.; Diaz Cuevas, A.; Vina, J.; Perez Martinez, G. Shifts in gut microbiota composition in an APP/PSS1 transgenic mouse model of Alzheimer's disease during lifespan. Lett. Appl. Microbiol. 2018, 66, 464-471. [CrossRef] [PubMed]

24. Odamaki, T.; Kato, K.; Sugahara, H.; Hashikura, N.; Takahashi, S.; Xiao, J.Z.; Abe, F.; Osawa, R. Age-related changes in gut microbiota composition from newborn to centenarian: A cross-sectional study. BMC Microbiol. 2016, 16, 90. [CrossRef] [PubMed]

25. Li, Z.; Zhu, H.; Guo, Y.; Du, X.; Qin, C. Gut microbiota regulate cognitive deficits and amyloid deposition in a model of Alzheimer's disease. J. Neurochem. 2020. [CrossRef] [PubMed]

26. Lee, H.J.; Lee, K.E.; Kim, J.K.; Kim, D.H. Suppression of gut dysbiosis by Bifidobacterium longum alleviates cognitive decline in 5XFAD transgenic and aged mice. Sci. Rep. 2019, 9, 11814. [CrossRef] [PubMed]

27. Minter, M.R.; Zhang, C.; Leone, V.; Ringus, D.L.; Zhang, X.; Oyler-Castrillo, P.; Musch, M.W.; Liao, F.; Ward, J.F.; Holtzman, D.M.; et al. Antibiotic-induced perturbations in gut microbial diversity influences neuro-inflammation and amyloidosis in a murine model of Alzheimer's disease. Sci. Rep. 2016, 6, 30028. [CrossRef] [PubMed]

28. Rao, J.; Qiao, Y.; Xie, R.; Lin, L.; Jiang, J.; Wang, C.; Li, G. Fecal microbiota transplantation ameliorates stress-induced depressionlike behaviors associated with the inhibition of glial and NLRP3 inflammasome in rat brain. J. Psychiatr. Res. 2021, 137, 147-157. [CrossRef]

29. Rutsch, A.; Kantsjo, J.B.; Ronchi, F. The Gut-Brain Axis: How Microbiota and Host Inflammasome Influence Brain Physiology and Pathology. Front. Immunol. 2020, 11, 604179. [CrossRef]

30. Shen, H.; Guan, Q.; Zhang, X.; Yuan, C.; Tan, Z.; Zhai, L.; Hao, Y.; Gu, Y.; Han, C. New mechanism of neuroinflammation in Alzheimer's disease: The activation of NLRP3 inflammasome mediated by gut microbiota. Prog. Neuropsychopharmacol. Biol. Psychiatry 2020, 100, 109884. [CrossRef]

31. Pellegrini, C.; Antonioli, L.; Calderone, V.; Colucci, R.; Fornai, M.; Blandizzi, C. Microbiota-gut-brain axis in health and disease: Is NLRP3 inflammasome at the crossroads of microbiota-gut-brain communications? Prog. Neurobiol. 2020, 101806. [CrossRef]

32. Pellegrini, C.; Antonioli, L.; Colucci, R.; Blandizzi, C.; Fornai, M. Interplay among gut microbiota, intestinal mucosal barrier and enteric neuro-immune system: A common path to neurodegenerative diseases? Acta Neuropathol. 2018, 136, 345-361. [CrossRef] [PubMed]

33. Kaufmann, F.N.; Costa, A.P.; Ghisleni, G.; Diaz, A.P.; Rodrigues, A.L.S.; Peluffo, H.; Kaster, M.P. NLRP3 inflammasome-driven pathways in depression: Clinical and preclinical findings. Brain Behav. Immun. 2017, 64, 367-383. [CrossRef] [PubMed]

34. Lowe, P.P.; Gyongyosi, B.; Satishchandran, A.; Iracheta-Vellve, A.; Cho, Y.; Ambade, A.; Szabo, G. Reduced gut microbiome protects from alcohol-induced neuroinflammation and alters intestinal and brain inflammasome expression. J. NeuroInflamm. 2018, 15, 298. [CrossRef] [PubMed]

35. Kanneganti, T.D.; Ozoren, N.; Body-Malapel, M.; Amer, A.; Park, J.H.; Franchi, L.; Whitfield, J.; Barchet, W.; Colonna, M.; Vandenabeele, P.; et al. Bacterial RNA and small antiviral compounds activate caspase-1 through cryopyrin/Nalp3. Nature 2006, 440, 233-236. [CrossRef] [PubMed]

36. Sutterwala, F.S.; Haasken, S.; Cassel, S.L. Mechanism of NLRP3 inflammasome activation. Ann. N. Y. Acad. Sci. 2014, 1319, 82-95. [CrossRef]

37. Shukla, P.K.; Meena, A.S.; Rao, V.; Rao, R.G.; Balazs, L.; Rao, R. Human Defensin-5 Blocks Ethanol and Colitis-Induced Dysbiosis, Tight Junction Disruption and Inflammation in Mouse Intestine. Sci. Rep. 2018, 8, 16241. [CrossRef] [PubMed] 
38. Shukla, P.K.; Meena, A.S.; Dalal, K.; Canelas, C.; Samak, G.; Pierre, J.F.; Rao, R. Chronic stress and corticosterone exacerbate alcohol-induced tissue injury in the gut-liver-brain axis. Sci. Rep. 2021, 11, 826. [CrossRef]

39. Shukla, P.K.; Meena, A.S.; Rao, R. Prevention and mitigation of alcohol-induced neuroinflammation by Lactobacillus plantarum by an EGF receptor-dependent mechanism. Nutr. Neurosci. 2020, 1-13. [CrossRef]

40. Shukla, P.K.; Meena, A.S.; Manda, B.; Gomes-Solecki, M.; Dietrich, P.; Dragatsis, I.; Rao, R. Lactobacillus plantarum prevents and mitigates alcohol-induced disruption of colonic epithelial tight junctions, endotoxemia, and liver damage by an EGF receptor-dependent mechanism. FASEB J. 2018, fj201800351R. [CrossRef]

41. Khan, M.M.; Xiao, J.; Patel, D.; LeDoux, M.S. DNA damage and neurodegenerative phenotypes in aged Ciz1 null mice. Neurobiol. Aging 2018, 62, 180-190. [CrossRef]

42. Khan, M.M.; Xiao, J.; Hollingsworth, T.J.; Patel, D.; Selley, D.E.; Ring, T.L.; LeDoux, M.S. Gnal haploinsufficiency causes genomic instability and increased sensitivity to haloperidol. Exp. Neurol. 2019, 318, 61-70. [CrossRef]

43. Thadathil, N.; Delotterie, D.F.; Xiao, J.; Hori, R.; McDonald, M.P.; Khan, M.M. DNA Double-Strand Break Accumulation in Alzheimer's Disease: Evidence from Experimental Models and Postmortem Human Brains. Mol. Neurobiol. 2021, 58, $118-131$. [CrossRef]

44. Chelakkot, C.; Ghim, J.; Ryu, S.H. Mechanisms regulating intestinal barrier integrity and its pathological implications. Exp. Mol. Med. 2018, 50, 103. [CrossRef]

45. Lee, B.; Moon, K.M.; Kim, C.Y. Tight Junction in the Intestinal Epithelium: Its Association with Diseases and Regulation by Phytochemicals. J. Immunol. Res. 2018, 2018, 2645465. [CrossRef] [PubMed]

46. Ayres, J.S. Inflammasome-microbiota interplay in host physiologies. Cell Host Microbe. 2013, 14, 491-497. [CrossRef] [PubMed]

47. Javed, H.; Thangavel, R.; Selvakumar, G.P.; Dubova, I.; Schwartz, N.; Ahmed, M.E.; Zaheer, S.; Kempuraj, D.; Iyer, S.; Zaheer, A.; et al. NLRP3 inflammasome and glia maturation factor coordinately regulate neuroinflammation and neuronal loss in MPTP mouse model of Parkinson's disease. Int. Immunopharmacol. 2020, 83, 106441. [CrossRef] [PubMed]

48. Heneka, M.T.; Kummer, M.P.; Stutz, A.; Delekate, A.; Schwartz, S.; Vieira-Saecker, A.; Griep, A.; Axt, D.; Remus, A.; Tzeng, T.C.; et al. NLRP3 is activated in Alzheimer's disease and contributes to pathology in APP/PS1 mice. Nature 2013, 493, 674-678. [CrossRef] [PubMed]

49. Campos-Acuna, J.; Elgueta, D.; Pacheco, R. T-Cell-Driven Inflammation as a Mediator of the Gut-Brain Axis Involved in Parkinson's Disease. Front. Immunol. 2019, 10, 239. [CrossRef] [PubMed]

50. Wu, S.C.; Cao, Z.S.; Chang, K.M.; Juang, J.L. Intestinal microbial dysbiosis aggravates the progression of Alzheimer's disease in Drosophila. Nat. Commun. 2017, 8, 24. [CrossRef] [PubMed]

51. Petrilli, V.; Dostert, C.; Muruve, D.A.; Tschopp, J. The inflammasome: A danger sensing complex triggering innate immunity. Curr. Opin. Immunol. 2007, 19, 615-622. [CrossRef] [PubMed]

52. Cattaneo, A.; Cattane, N.; Galluzzi, S.; Provasi, S.; Lopizzo, N.; Festari, C.; Ferrari, C.; Guerra, U.P.; Paghera, B.; Muscio, C.; et al. Association of brain amyloidosis with pro-inflammatory gut bacterial taxa and peripheral inflammation markers in cognitively impaired elderly. Neurobiol. Aging 2017, 49, 60-68. [CrossRef] [PubMed]

53. Saresella, M.; La Rosa, F.; Piancone, F.; Zoppis, M.; Marventano, I.; Calabrese, E.; Rainone, V.; Nemni, R.; Mancuso, R.; Clerici, M. The NLRP3 and NLRP1 inflammasomes are activated in Alzheimer's disease. Mol. Neurodegener. 2016, 11, 23. [CrossRef] [PubMed]

54. Heneka, M.T.; Carson, M.J.; El Khoury, J.; Landreth, G.E.; Brosseron, F.; Feinstein, D.L.; Jacobs, A.H.; Wyss-Coray, T.; Vitorica, J.; Ransohoff, R.M.; et al. Neuroinflammation in Alzheimer's disease. Lancet Neurol. 2015, 14, 388-405. [CrossRef]

55. Ahmad, M.H.; Fatima, M.; Mondal, A.C. Influence of microglia and astrocyte activation in the neuroinflammatory pathogenesis of Alzheimer's disease: Rational insights for the therapeutic approaches. J. Clin. Neurosci. 2019, 59, 6-11. [CrossRef] [PubMed]

56. Ma, Q.; Xing, C.; Long, W.; Wang, H.Y.; Liu, Q.; Wang, R.F. Impact of microbiota on central nervous system and neurological diseases: The gut-brain axis. J. Neuroinflamm. 2019, 16, 53. [CrossRef] [PubMed]

57. Cox, L.M.; Weiner, H.L. Microbiota Signaling Pathways that Influence Neurologic Disease. Neurotherapeutics 2018, 15, 135-145. [CrossRef] [PubMed]

58. Wang, H.; Yang, F.; Xin, R.; Cui, D.; He, J.; Zhang, S.; Sun, Y. The gut microbiota attenuate neuroinflammation in manganese exposure by inhibiting cerebral NLRP3 inflammasome. Biomed Pharmacother 2020, 129, 110449. [CrossRef]

59. Sun, B.L.; Li, W.W.; Wang, J.; Xu, Y.L.; Sun, H.L.; Tian, D.Y.; Wang, Y.J.; Yao, X.Q. Gut Microbiota Alteration and Its Time Course in a Tauopathy Mouse Model. J. Alzheimers Dis. 2019, 70, 399-412. [CrossRef] [PubMed]

60. Chen, C.; Ahn, E.H.; Kang, S.S.; Liu, X.; Alam, A.; Ye, K. Gut dysbiosis contributes to amyloid pathology, associated with $\mathrm{C} /$ EBPbeta/AEP signaling activation in Alzheimer's disease mouse model. Sci. Adv. 2020, 6, eaba0466. [CrossRef] [PubMed]

61. Harach, T.; Marungruang, N.; Duthilleul, N.; Cheatham, V.; Mc Coy, K.D.; Frisoni, G.; Neher, J.J.; Fak, F.; Jucker, M.; Lasser, T.; et al. Reduction of Abeta amyloid pathology in APPPS1 transgenic mice in the absence of gut microbiota. Sci. Rep. 2017, 7, 41802. [CrossRef] [PubMed]

62. Shin, W.; Kim, H.J. Intestinal barrier dysfunction orchestrates the onset of inflammatory host-microbiome cross-talk in a human gut inflammation-on-a-chip. Proc. Natl. Acad. Sci. USA 2018, 115, E10539-E10547. [CrossRef]

63. Vancamelbeke, M.; Vermeire, S. The intestinal barrier: A fundamental role in health and disease. Expert Rev. Gastroenterol. Hepatol. 2017, 11, 821-834. [CrossRef] [PubMed] 
64. Bischoff, S.C.; Barbara, G.; Buurman, W.; Ockhuizen, T.; Schulzke, J.D.; Serino, M.; Tilg, H.; Watson, A.; Wells, J.M. Intestinal permeability-a new target for disease prevention and therapy. BMC Gastroenterol. 2014, 14, 189. [CrossRef] [PubMed]

65. Barcenilla, A.; Pryde, S.E.; Martin, J.C.; Duncan, S.H.; Stewart, C.S.; Henderson, C.; Flint, H.J. Phylogenetic relationships of butyrate-producing bacteria from the human gut. Appl. Environ. Microbiol. 2000, 66, 1654-1661. [CrossRef] [PubMed]

66. Yang, X.; Yu, D.; Xue, L.; Li, H.; Du, J. Probiotics modulate the microbiota-gut-brain axis and improve memory deficits in aged SAMP8 mice. Acta Pharm. Sin B 2020, 10, 475-487. [CrossRef] [PubMed]

67. Wang, Y.; An, Y.; Ma, W.; Yu, H.; Lu, Y.; Zhang, X.; Wang, Y.; Liu, W.; Wang, T.; Xiao, R. 27-Hydroxycholesterol contributes to cognitive deficits in APP/PS1 transgenic mice through microbiota dysbiosis and intestinal barrier dysfunction. J. Neuroinflamm. 2020, 17, 199. [CrossRef]

68. Stadlbauer, V.; Engertsberger, L.; Komarova, I.; Feldbacher, N.; Leber, B.; Pichler, G.; Fink, N.; Scarpatetti, M.; Schippinger, W.; Schmidt, R.; et al. Dysbiosis, gut barrier dysfunction and inflammation in dementia: A pilot study. BMC Geriatr. 2020, 20, 248. [CrossRef] [PubMed]

69. Tran, L.; Greenwood-Van Meerveld, B. Age-associated remodeling of the intestinal epithelial barrier. J. Gerontol. A Biol. Sci. Med. Sci. 2013, 68, 1045-1056. [CrossRef] [PubMed]

70. Clairembault, T.; Leclair-Visonneau, L.; Coron, E.; Bourreille, A.; Le Dily, S.; Vavasseur, F.; Heymann, M.F.; Neunlist, M.; Derkinderen, P. Structural alterations of the intestinal epithelial barrier in Parkinson's disease. Acta Neuropathol. Commun. $2015,3,12$. [CrossRef]

71. Stan, T.L.; Soylu-Kucharz, R.; Burleigh, S.; Prykhodko, O.; Cao, L.; Franke, N.; Sjogren, M.; Haikal, C.; Hallenius, F.; Bjorkqvist, M. Increased intestinal permeability and gut dysbiosis in the R6/2 mouse model of Huntington's disease. Sci. Rep. 2020, 10, 18270. [CrossRef] [PubMed]

72. Wu, S.; Yi, J.; Zhang, Y.G.; Zhou, J.; Sun, J. Leaky intestine and impaired microbiome in an amyotrophic lateral sclerosis mouse model. Physiol. Rep. 2015, 3. [CrossRef] [PubMed]

73. Ulluwishewa, D.; Anderson, R.C.; McNabb, W.C.; Moughan, P.J.; Wells, J.M.; Roy, N.C. Regulation of tight junction permeability by intestinal bacteria and dietary components. J. Nutr. 2011, 141, 769-776. [CrossRef] [PubMed]

74. Choi, V.M.; Herrou, J.; Hecht, A.L.; Teoh, W.P.; Turner, J.R.; Crosson, S.; Bubeck Wardenburg, J. Activation of Bacteroides fragilis toxin by a novel bacterial protease contributes to anaerobic sepsis in mice. Nat. Med. 2016, 22, 563-567. [CrossRef] [PubMed]

75. Rogers, G.B.; Keating, D.J.; Young, R.L.; Wong, M.L.; Licinio, J.; Wesselingh, S. From gut dysbiosis to altered brain function and mental illness: Mechanisms and pathways. Mol. Psychiatry 2016, 21, 738-748. [CrossRef]

76. Zhao, Y.; Lukiw, W.J. Microbiome-generated amyloid and potential impact on amyloidogenesis in Alzheimer's disease (AD). J. Nat. Sci. 2015, 1, e138.

77. Zhang, R.; Miller, R.G.; Gascon, R.; Champion, S.; Katz, J.; Lancero, M.; Narvaez, A.; Honrada, R.; Ruvalcaba, D.; McGrath, M.S. Circulating endotoxin and systemic immune activation in sporadic amyotrophic lateral sclerosis (sALS). J. Neuroimmunol. 2009, 206, 121-124. [CrossRef]

78. Carabotti, M.; Scirocco, A.; Maselli, M.A.; Severi, C. The gut-brain axis: Interactions between enteric microbiota, central and enteric nervous systems. Ann. Gastroenterol. 2015, 28, 203-209. [PubMed]

79. Freeman, L.; Guo, H.; David, C.N.; Brickey, W.J.; Jha, S.; Ting, J.P. NLR members NLRC4 and NLRP3 mediate sterile inflammasome activation in microglia and astrocytes. J. Exp. Med. 2017, 214, 1351-1370. [CrossRef]

80. Ising, C.; Venegas, C.; Zhang, S.; Scheiblich, H.; Schmidt, S.V.; Vieira-Saecker, A.; Schwartz, S.; Albasset, S.; McManus, R.M.; Tejera, D.; et al. NLRP3 inflammasome activation drives tau pathology. Nature 2019, 575, 669-673. [CrossRef]

81. Tejera, D.; Mercan, D.; Sanchez-Caro, J.M.; Hanan, M.; Greenberg, D.; Soreq, H.; Latz, E.; Golenbock, D.; Heneka, M.T. Systemic inflammation impairs microglial Abeta clearance through NLRP3 inflammasome. EMBO J. 2019, 38, e101064. [CrossRef] [PubMed]

82. Hirota, S.A.; Ng, J.; Lueng, A.; Khajah, M.; Parhar, K.; Li, Y.; Lam, V.; Potentier, M.S.; Ng, K.; Bawa, M.; et al. NLRP3 inflammasome plays a key role in the regulation of intestinal homeostasis. Inflamm. Bowel Dis. 2011, 17, 1359-1372. [CrossRef] [PubMed]

83. Zhang, Y.; Huang, R.; Cheng, M.; Wang, L.; Chao, J.; Li, J.; Zheng, P.; Xie, P.; Zhang, Z.; Yao, H. Gut microbiota from NLRP3deficient mice ameliorates depressive-like behaviors by regulating astrocyte dysfunction via circHIPK2. Microbiome 2019, 7, 116. [CrossRef] [PubMed]

84. Wood, H. Dementia: Peripheral inflammation could be a prodromal indicator of dementia. Nat. Rev. Neurol. 2018, 14, 127. [CrossRef]

85. Gyoneva, S.; Davalos, D.; Biswas, D.; Swanger, S.A.; Garnier-Amblard, E.; Loth, F.; Akassoglou, K.; Traynelis, S.F. Systemic inflammation regulates microglial responses to tissue damage in vivo. Glia 2014, 62, 1345-1360. [CrossRef] [PubMed]

86. Manocha, G.D.; Floden, A.M.; Miller, N.M.; Smith, A.J.; Nagamoto-Combs, K.; Saito, T.; Saido, T.C.; Combs, C.K. Temporal progression of Alzheimer's disease in brains and intestines of transgenic mice. Neurobiol. Aging 2019, 81, 166-176. [CrossRef] [PubMed]

87. Semar, S.; Klotz, M.; Letiembre, M.; Van Ginneken, C.; Braun, A.; Jost, V.; Bischof, M.; Lammers, W.J.; Liu, Y.; Fassbender, K.; et al. Changes of the enteric nervous system in amyloid-beta protein precursor transgenic mice correlate with disease progression. J. Alzheimers Dis. 2013, 36, 7-20. [CrossRef] [PubMed] 